\title{
Maintenance of the inotropic effect of digoxin on long-term treatment
}

\author{
B E GRIFFITHS, W J PENNY, M J LEWIS, A H HENDERSON
}

\begin{abstract}
M-mode echocardiograms and systolic time intervals were recorded before and six weeks after stopping digoxin in 11 patients in sinus rhythm to see whether the inotropic effect of digoxin was maintained with long-term treatment. Significant changes indicating a reduction in inotropic state on stopping digoxin were observed in the group. Clinical deterioration occurred in only one patient, associated with evidence of initially impaired cardiac function rather than an atypical response to digoxin.

This study provides evidence that chronic digoxin treatment does continue to exert a positive inotropic effect.
\end{abstract}

\section{Introduction}

Whether the inotropic effect of cardiac glycosides is maintained with long-term treatment has recently been questioned. ${ }^{12}$ Several groups have reported that stopping maintenance digoxin treatment often results in no symptomatic deterioration when the patient is in sinus rhythm, ${ }^{3-8}$ but the results of non-invasive studies have been conflicting. ${ }^{1}{ }^{8-15}$ We studied a group of patients in sinus rhythm by recording $M$-mode echocardiograms and systolic time intervals on three consecutive days while having digoxin treatment and on three consecutive days six weeks after substituting placebo for digoxin.

Department of Cardiology, Welsh National School of Medicine, Heath Park, Cardiff

B E GRIFFITHS, MB, MRCP, lecturer

W J PENNY, MB, MRCP, registrar

A H HENDERSON, MB, FRCP, professor

Department of Pharmacology and Therapeutics, Welsh National School of Medicine, Cardiff

$M$ J LEWIS, PHD, MB, senior lecturer

\section{Patients and Methods}

The study group consisted of 11 patients (aged 20-65 years; six men), treated continuously with digoxin for 10 months or more. The dosage of digoxin was constant and serum values six hours after the morning dose were within the therapeutic range $(1.2-1.6 \mathrm{nmol} / \mathrm{l})$ in all patients. All patients were in sinus rhythm with no evidence of impaired conduction. None had signs of congestive failure, two were in New York Heart Association class III, three in class II, and six in class I. Diuretics were being taken by the two patients in class III (frusemide $80 \mathrm{mg}$ every morning and spironolactone $100 \mathrm{mg}$ every morning in one, frusemide $80 \mathrm{mg}$ every morning in the other) and by two of the patients in class II (frusemide $40 \mathrm{mg}$ every morning in one and bendrofluazide $5 \mathrm{mg}$ every morning in the other). The underlying diagnosis was coronary artery disease in four patients, rheumatic valve disease in four, mitral valve replacement one year earlier in one, closure of atrial septal defect three years earlier in one, and no known disease in one. The initial reason for starting digoxin treatment had been recorded as pulmonary oedema in three patients and palpitations in four.

All patients gave their informed consent to the study. Preliminary assessment included full clinical evaluation; measurement of serum electrolyte, urea, haemoglobin, and digoxin concentrations; chest radiograph; and electrocardiogram (ECG). Each patient then had an $\mathrm{M}$-mode echocardiogram and recordings of ECG, phonocardiogram, and carotid pulse pressure for measurement of systolic time intervals at the same time of day on each of three consecutive days. Placebo tablets were then substituted for digoxin tablets without the patients' knowledge. Other treatment continued unchanged. Patients were seen every two weeks for clinical assessment and measurement of heart rate, blood pressure, and body weight. Six weeks later (except in the one patient who deteriorated, see below) an echocardiogram and systolic time intervals were again recorded on three consecutive days, as before. Chest radiographs and ECGs were repeated on the last of these visits.

Echocardiography-M-mode echocardiograms were recorded with a Smith Kline French Echoline using a $2 \cdot 25 \mathrm{~m} \mathrm{~Hz}$ focused transducer coupled to a Cambridge Multichannel Recorder. Each patient rested for 10 minutes before the investigation. A careful note was made of the positions of the patient and of the transducer, and these positions were kept constant at each subsequent investigation (all recorded by $\mathrm{BEG}$ ). Left ventricular dimensions were obtained just below the mitral valve after an aorta-left ventricle scan. The internal cavity dimensions of the left ventricle at end diastole $\left(\right.$ LVID $\left._{d}\right)$ were measured at the peak of the $\mathrm{R}$ wave of a simultaneously recorded ECG and at end systole (LVIDs) at the nadir of septal motion 
(fig 1). The data were measured blind by the same observer (BEG) using the leading edge method throughout. Five cardiac cycles were analysed on each occasion. The following indices of left ventricular function were derived:

$$
\text { Fractional shortening }=\frac{\text { LVID }_{d}-\text { LVID }_{s}}{\text { LVID }_{d}}
$$

Velocity of circumferential fibre shortening $=\frac{\text { LVID }_{d}-L_{\text {LVID }}}{\operatorname{LVID}_{d} \times E T}$

Ejection time (ET) was obtained from the indirect carotid pulse tracing. The reproducibility of echocardiographic dimension measurements was evaluated by recording echocardiograms from eight normal subjects repeatedly over six weeks using the same technique. The coefficients of variation of $\mathrm{LVID}_{\mathrm{d}}, \mathrm{LVID}_{\mathrm{s}}$, and fractional shortening recorded and measured blind by the same investigator (BEG) on day 0 , day 1 , day 7 , and day 42 were $2 \%, 4 \%$, and $6 \%$ respectively.

Systolic time intervals-Recordings for systolic time interval measurements were obtained immediately after the M-mode echocardiograms. The recordings were made at a paper speed of $100 \mathrm{~mm} / \mathrm{s}$ (fig 2). The electrocardiographic lead that showed most clearly the onset of ventricular depolarisation was used. A microphone was placed over the upper part of the praecordium in a position optimal for recording the initial high frequency vibrations of the second heart sound. The right carotid artery pulse was recorded with a funnel-shaped pick-up air-coupled to a Cambridge Pulse Transducer (Type 53642). In each case the pulse wave was at least $4 \mathrm{~cm}$ in amplitude and had a distinct wave form. The following phases of

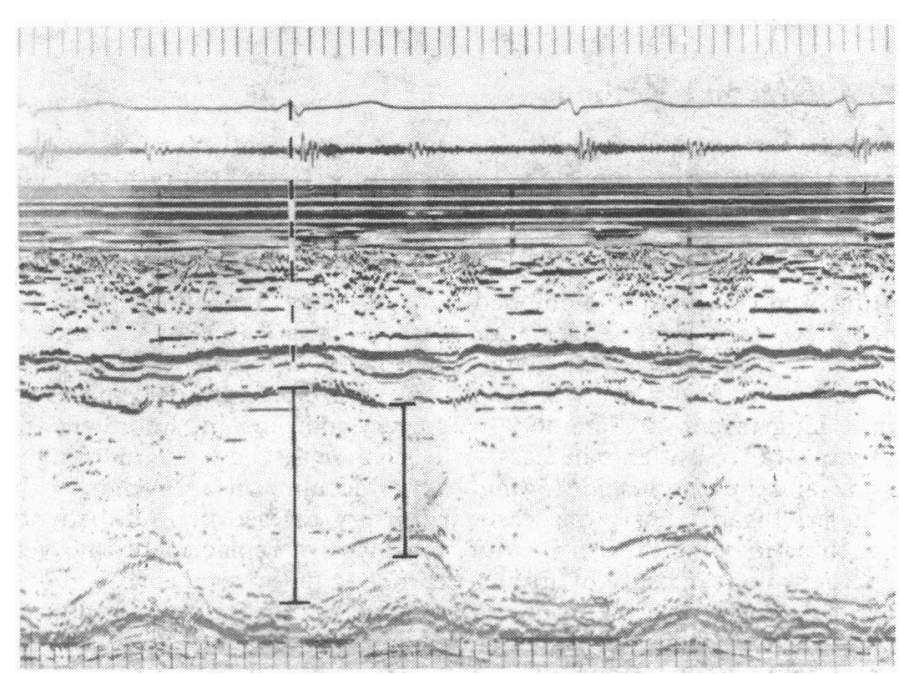

FIG $1-M$-mode echocardiogram of left ventricle. Left ventricular enddiastolic dimension is measured as distance between endocardial surface of left side of interventricular septum and posterior wall at peak of $R$ wave of simultaneously recorded electrocardiogram. End-systolic dimension is measured at the nadir of septal motion.
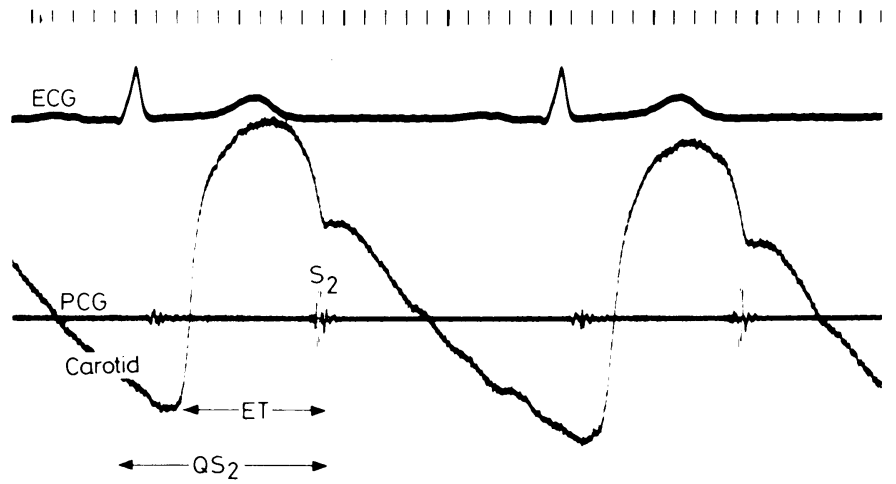

FIG 2-Simultaneous recording of heart sounds (PCG), carotid pulse, and electrocardiogram (ECG), showing measurement of ejection time (ET) and total electromechanical systole $\left(\mathrm{QS}_{2}\right)$. the cardiac cycle were measured: (a) total electromechanical systole $\left(\mathrm{QS}_{2}\right)$, measured from the onset of the QRS complex to the first high-frequency vibrations of the second heart sound; $(b)$ left ventricular ejection time, measured from the beginning of the upstroke to the trough of the incisura of the carotid arterial pulse tracing; and (c) pre-ejection period, derived by subtracting ejection time from $\mathrm{QS}_{2}$.

All intervals were calculated from 10 consecutive beats and are given as the mean of these. Data for $\mathrm{QS}_{2}$ and pre-ejection period o are given as the difference in each case between the observed value and the value predicted from the normal regression equation for heart rate and sex. ${ }^{16}$

Blood pressure-Blood pressure was measured by sphygmomanometer, the diastolic pressure being taken as the fifth phase of the Korotkof sounds. Mean arterial pressure was calculated as $1 / 3$ (systolic-diastolic pressure) + diastolic pressure.

Analysis of data-Analysis of variance and Student's $t$ test for paired data were used for statistical analysis, $p<0.05$ being taken as the limit of significance. Data are shown as the mean \pm standard error.

\section{Results}

Figs 3 and 4 show the data before and after stopping chronic digoxin treatment. Analysis of variance showed no difference between the three consecutive measurements of any variable in either state. The mean of each series of three measurements is therefore shown in the figures. There was no change in heart rate $(81 \pm 5$ to $83 \pm 7$ beats/ min), mean arterial pressure $(93 \pm 2$ to $90+2 \mathrm{~mm} \mathrm{Hg}$ ), or body weight $(66+3$ to $67+3 \mathrm{~kg})$. There were significant increases in $\infty$ LVID $_{\mathrm{d}}(5 \cdot 0 \pm 0.3$ to $5 \cdot 2 \pm 0.3 \mathrm{~cm}(\mathrm{p}<0.01))$ and $\operatorname{LVID}_{\mathrm{s}}(3.5 \pm 0.3$ to $\overrightarrow{0}$

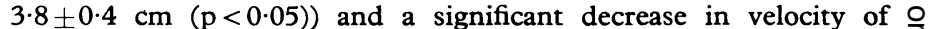
circumferential fibre shortening $(1.08 \pm 0.1$ to $0.95 \pm 0.1 / \mathrm{s}(\mathrm{p}<0.05))$ with a non-significant decrease in fractional shortening $(30 \pm 2$ to $\overrightarrow{0}$ $28 \pm 3 \%)$. There were increases in the difference between predicted $ᄃ$ and actual values for $\mathrm{QS}_{2}(-7 \pm 5$ to $8 \pm 4 \mathrm{~ms}(\mathrm{p}<0 \cdot 02))$, for ejection time $(+7 \pm 6$ to $+17 \pm 7 \mathrm{~ms}(\mathrm{p}<0.05))$, and for pre-ejection period $(-12+7$ to $-5+9 \mathrm{~ms}$ (non-significant)).

Worsening dyspnoea with clinical and radiological evidence of
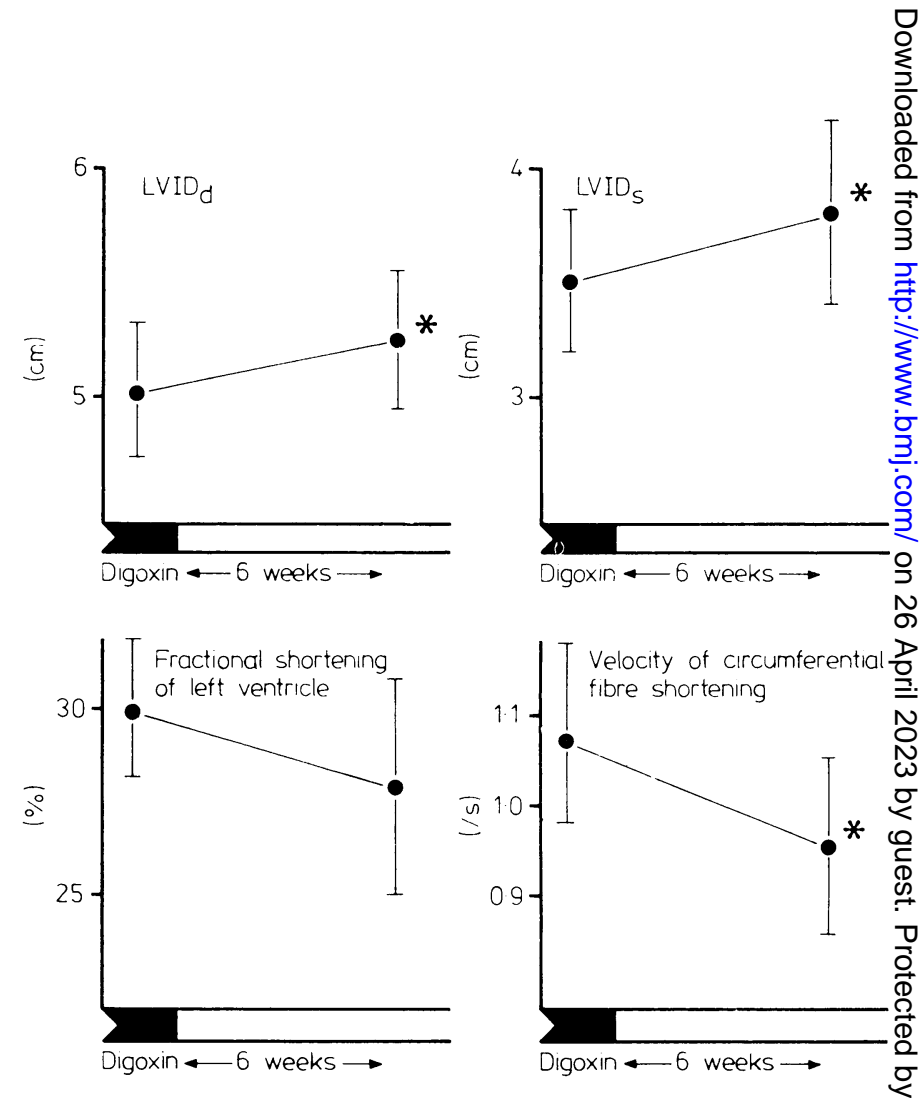

FIG 3-Echocardiographic measurements (mean $\pm \mathrm{SE}, \mathrm{n}=11$ ) obtained $\bigcirc$ before and six weeks after stopping chronic digoxin treatment. Significant differences are shown with asterisk. LVID ${ }_{\mathrm{d}}=$ Internal cavity dimension of the left ventricle at end diastole. $\mathrm{LVID}_{\mathrm{s}}=$ Internal cavity dimension of the left $\frac{\mathrm{Q}}{\bar{T}}$ ventricle at end systole. 
pulmonary oedema occurred 10 days after stopping digoxin in one of the patients in class III (the patient taking both frusemide and spironolactone). This patient had the "worst" overall initial values LVID $_{\mathrm{d}} 6.7 \mathrm{~cm}$, LVID $_{\mathrm{s}} 5.5 \mathrm{~cm}$, fractional shortening $19 \%$, velocity of circumferential fibre shortening $0.77 / \mathrm{s}$, pre-ejection period $+37 \mathrm{~ms}$, ejection time $-40 \mathrm{~ms}$ ). Deterioration in these values measured on days 10,11 , and 12 after stopping digoxin was only average for the group as a whole. Digoxin treatment was restarted at the original dosage with consequent recovery. Excluding this patient from the statistical analysis did not alter the significance of any of the changes noted in the total group.

\section{Discussion}

This non-invasive study showed significant changes in left ventricular function six weeks after stopping long-term digoxin treatment. We took care to ensure that treatment had been long maintained, that serum concentrations of digoxin were within the therapeutic range, that a sufficiently long interval was allowed to ensure myocardial washout of digoxin, that other treatment remained unchanged, and that biological and technical scatter was minimised by recording three serial measurements under standardised conditions in each state. The observed increase in LVIDs and the reduction in the velocity of circumferential fibre shortening without increase in arterial pressure implies a decrease in inotropic state when digoxin was stopped. The increase in LVID $_{\mathrm{d}}$ may be regarded as the normal adaptive response to this decrease in the absence of any reduction of heart rate. Likewise, the direction of the changes in systolic time intervals implies a decrease in inotropic state in the absence of any evidence of increased load. In one patient there was clinical evidence of a decline in left ventricular function sufficient to result in pulmonary oedema, which resolved when the same dose of digoxin was restarted. Our study thus provides strong evidence that digoxin continues to exert a positive inotropic effect in long-term use.
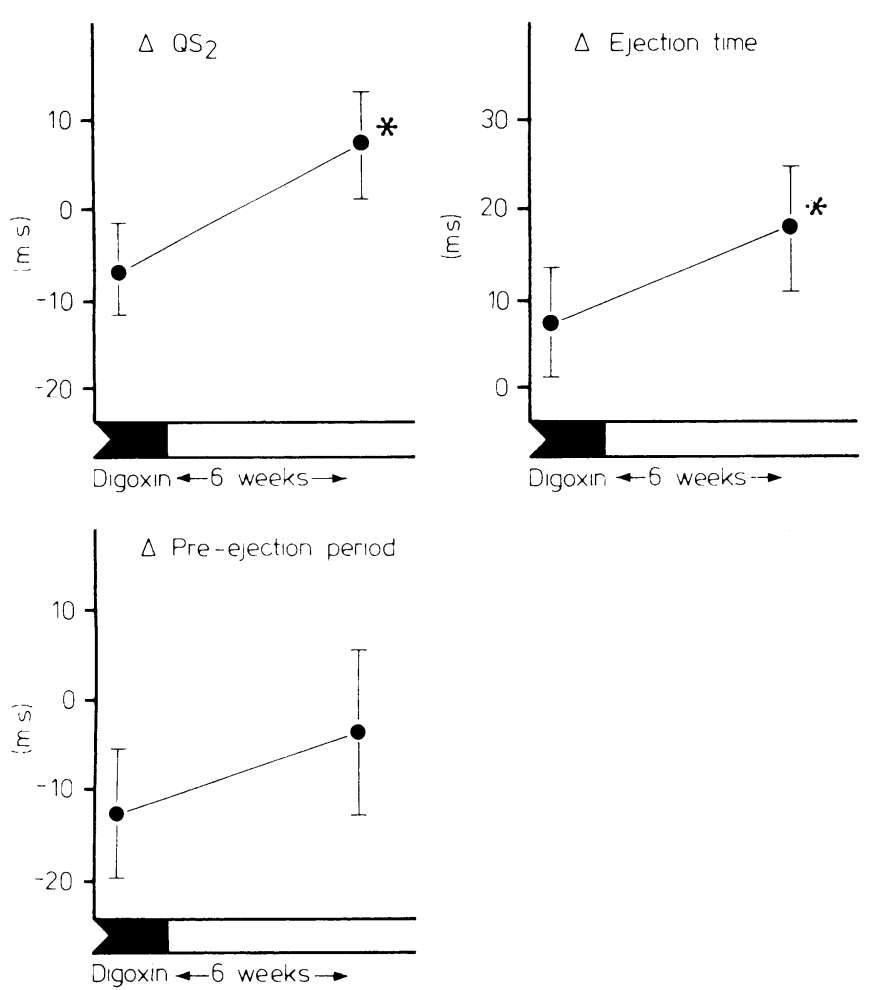

FIG 4-Systolic time interval measurements (mean $\pm S E, n=11$ ) obtained before and six weeks after stopping chronic digoxin treatment. Significant differences are shown with an asterisk. Data are expressed as the difference $(\triangle)$ in each case between the observed value and the value predicted from the normal regression equation for the heart rate and sex. $\mathrm{QS}_{2}=$ Total electromechanical systole.
Acute treatment with cardiac glycosides increases inotropic state in the presence or absence of heart failure, but it augments cardiac output only when heart failure ${ }^{17-22}$ is present. The lack of clinical deterioration on stopping digoxin treatment may similarly reflect the fact that such patients are no longer in heart failure. The frequent absence of clinical deterioration when long-term digoxin treatment is stopped has been widely emphasised, ${ }^{3-9}{ }^{23-25}$ but it is important to note too that deterioration did ensue in some $16 \%$ of the 341 patients collectively reported in these studies. A recent haemodynamic study by Arnold $e t$ al of nine patients with more severe heart failure than those in our study (four patients in class II, five patients in class III) also showed a reduction in inotropic state when long-term digoxin treatment was stopped and clinical deterioration in five patients, four of whom were in class III. ${ }^{26}$

On the basis of erythrocyte studies Pugh et al have suggested that some patients develop tolerance to digoxin whereas others do not and that lack of tolerance may distinguish those whose circulatory state deteriorates on stopping digoxin. ${ }^{27}$ The evidence of our study and that of Arnold $e t a l^{26}$ does not support this view.

We would suggest that clinical deterioration on stopping long-term digoxin treatment is related to the underlying cardiac state rather than to any peculiarity in the response to digoxin.

We thank Dr R G Newcombe, department of medical statistics, Welsh National School of Medicine, Cardiff, for the statistical analysis.

\section{References}

${ }^{1}$ Davidson C, Gibson D. Clinical significance of positive inotropic action of digoxin in patients with left ventricular disease. Br Heart $\mathcal{f} 1973 ; 35$ : 970-6.

${ }^{2}$ Anonymous. Digoxin in sinus rhythm. Br Med f 1979;i:1103-4.

${ }^{3}$ Starr I, Luchi RJ. Blind study on the action of digitoxin on elderly women. Am Heart f 1969;78:740-51

${ }^{4}$ Dall JLC. Maintenance digoxin in elderly patients. Br Med $\mathcal{f} 1970$;ii: 705-6.

${ }^{5}$ Liverpool Therapeutics Group. Use of digitalis in general practice. Br Med f 1978;ii:673-5.

${ }^{6}$ Hull SM, Mackintosh A. Discontinuation of maintenance digoxin therapy in general practice. Lancet 1977 ;ii:1054-5.

${ }^{7}$ McHaffie D, Purcell H, Mitchell-Heggs P, Guz A. The clinical value of digoxin in patients with heart failure and sinus thythm. Quart $\mathcal{f}$ Med 1978;47:401-19.

${ }^{8} \mathrm{Johnston} \mathrm{GD}, \mathrm{McD}$ evitt DG. Is maintenance digoxin necessary in patients with sinus rhythm? Lancet 1979;i:567-70.

${ }^{9}$ Dobbs SM, Kenyon WI, Dobbs RJ. Maintenance digoxin after an episode of heart failure: placebo-controlled trial in out-patients. $\mathrm{Br}$ Med $\mathcal{F}$ $1977 ; \mathrm{i}: 749-52$.

10 Gomes JA, Calderon J, Zaman Q, Marino ND, Friedman HS. Improvement in cardiac performance after maintenance digoxin in alcoholic cardiomyopathy: an echocardiographic study. Circulation 1975;51/52 suppl II 49 .

${ }^{11}$ O'Rourke RA, Henning H, Theroux P, Crawford MH, Ross J. Favourable effects of orally administered digoxin on left heart size and ventricular wall motion in patients with previous myocardial infarction. $A m \mathcal{F}$ Cardiol 1976;37:708-15.

${ }^{12}$ Crawford MH, Karliner JS, O'Rourke RA. Favourable effects of oral maintenance digoxin therapy on left ventricular performance in noimal subjects: echocardiographic study. Am $\mathcal{F}$ Cardiol 1976;38:843-7.

${ }^{13}$ Vogel R, Frischknecht J, Steele P. Short and long-term effects of digitalis on resting and post-handgrip haemodynamics in patients with coronary artery disease. Am $\mathcal{F}$ Cardiol 1977;40:171-6.

${ }^{14}$ Kleiman JH, Ingels NB, Daughters G, Stinson EB, Alderman EL, Goldman RH. Left ventricular dynamics during long-term digoxin treatment in patients with stable coronary artery disease. Am $\mathcal{F}$ Cardiol 1978; $41: 937-42$.

${ }^{15}$ Fleg JL, Gottlieb SH, Lakatta EG. Is digitalis really useful in the therapy of chronic congestive heart failure? Circulation $\mathbf{1 9 7 9 ; 5 9 / 6 0}$ suppl II: 178.

${ }^{16}$ Weissler AM, Harris WS, Schoenfeld CD. Systolic time intervals in heart failure in man. Circulation 1968;2:149-59.

17 Harvey RM, Ferrer MI, Cathcart RT, Richards DW, Jr, Cournand A. Some effects of digoxin upon heart and circulation in man; digoxin in left ventricular failure. Am f Med 1949;7:439-53.

${ }^{18}$ Harvey RM, Ferrer MI, Cathcart RT, Alexander JK. Some effects of digoxin on the heart and circulation in man. Digoxin in enlarged hearts not in clinical congestive failure. Circulation 1951;4:366-77. 
19 Dresdale DT, Yuleoglu YZ, Michtom RJ, Schultz M, Lunger M. Effects of Lanatoside $\mathrm{C}$ on cardiovascular haemodynamics. Acute digitalizing dose in subjects with normal hearts and with heart disease without failure. Am 7 Cardiol 1959;4:88-99.

${ }^{20}$ Selzer A, Hultgren HN, Ebnother CL, Bradley HW, Stone AD. Effect of digoxin on the circulation in normal man. Br Heart $\mathcal{f} 1959 ; 21$ : 335-42.

${ }^{21}$ Mason DT, Braunwald E. Studies on digitalis IX Effects of ouabain on the non-failing human heart. $\mathcal{f}$ Clin Invest 1963;42:1105-11.

${ }^{22}$ Sonnenblick EH, Williams JF, Glick G, Mason DT, Braunwald E. Studies on digitalis XV Effects of cardiac glycosides on myocardial force-velocity relations in the non-failing human heart. Circulation 1966;34:532-9.

${ }^{23}$ Priddle WW, Rose $M$. Curtailing therapy in a home for the aged, with special reference to digitalis, diuretics and low-sodium diet. $\mathcal{F} \mathrm{Am}$ Ger Soc 1966;14:731-4.
${ }^{24}$ Fonrose HA, Ahlbaum N, Bugatch E, Cohen M, Genovese C, Kelly J. The efficacy of digitalis withdrawal in an institutional aged population. 7 Am Ger Soc 1974;22:208-11.

${ }^{25}$ Krakauer R, Petersen B. The effects of discontinuing maintenance digoxin therapy; a study of elderly cardiac patients in sinus rhythm. Dan Med Bull 1979;26:10-13.

${ }^{26}$ Arnold SB, Byrd RC, Meister W, Melmon K, Cheitlin MD, Bristow JD, Parmley WW, Chatterjee K. Long-term digitalis therapy improves left ventricular function in heart failure. $N$ Engl f Med 1980;303:1443-8.

${ }^{27}$ Pugh SE, White NJ, Aronson JK, Grahame-Smith DG, Carver JG. Erythrocytic digoxin receptor numbers and activity: relation to clinical changes following digoxin withdrawal after long-term treatment for heart failure in sinus rhythm. Br $\mathcal{F}$ Pharmacol (in press).

\title{
Purified interferon as protection against rhinovirus infection
}

\author{
G M SCOTT, R J PHILLPOTTS, J WALLACE, D S SECHER，K CANTELL，D A J TYRRELL
}

\begin{abstract}
In a double-blind placebo-controlled study a preparation of human leucocyte interferon purified by affinity chromatography using a monoclonal antibody and applied by repeated nasal sprays reduced the incidence and severity of colds in volunteers challenged with human rhinovirus 9. Although interferon itself caused some symptoms, these were minor compared with the clinical colds. Interferon activity was still detectable in nasal washings as long as $\mathbf{2 6}$ hours after the last dose in about half the volunteers on active treatment.
\end{abstract}

\section{Introduction}

In 1973 Merigan et $a l^{1}$ showed that $14 \times 10^{6}$ units (about $50 \mu \mathrm{g}$ ) of partially purified human leucocyte interferon could protect volunteers against infection with rhinovirus 4 . Since then better methods of application iave been looked for, so that a lower dose can be used..$^{2-5}$ The lack of interferon available for clinical trials over the last decade has been eased recently by the cloning of human interferon genes in bacteria. ${ }^{6}$ As the first in a series of experiments to examine the effects of new interferon preparations on respiratory infections, the previous stucil ${ }^{1}$ has been repeated using highly purified human leucocyte interferon.

\section{Subjects and methods}

Interferon-This was induced in pooled buffy-coat leucocytes stimulated with Sendai virus and partially purified by selective

\footnotetext{
Medical Research Council Common Cold Unit, Harvard Hospital, Salisbury, Wiltshire

G M SCOTT, MRCP, scientific staff member

R J PHILLPOTTS, PHD, scientific staff member

J WALLACE, MD, FRCP, clinical administrator

D A J TYRRELL, FRCP, FRS, director

Medical Research Council Laboratory of Molecular Biology, Cambridge

D S SECHER, PHD, scientific staff member

Public Health Laboratory, Helsinki, Finland

K CANTELL, MD, professor of virology
}

precipitation. ${ }^{7}$ It was purified by immunoadsorption chromatography on monoclonal antibody NK2 bound to Sepharose $4 \mathrm{~B}(4 \times 4 \mathrm{~cm}){ }^{8}$ The preparation, purification, and checks of sterility of interferon and placebo (phosphate-buffered saline with human serum albumin $2 \mathrm{mg} / \mathrm{ml}$ ) have been described. ${ }^{9}$ The yield of interferon was $53 \%$ by immunoradiometric assay and the specific activity of the purified interferon (NK2) was $1.6 \times 10^{8} \mu / \mathrm{mg}$ protein. The antiviral activity was $10^{7} \mathrm{U} / \mathrm{ml}$ by plaque reduction of vesicular stomatitis virus in monkey kidney (V3) cells, by inhibition of Semliki Forest virus RNA synthesis in embryonic bovine tracheal cells, and by immunoradiometric assay. ${ }^{1 "}$ Both interferon and placebo preparations contained less than $2.5 \mu \mathrm{g} / \mathrm{l}$ endotoxin by limulus lysate assay. Interferon and placebo solutions were indistinguishable and coded in four batches (two from each treatment group).

Virus-Rhinovirus 9, obtained from a filtered nasal washing pool held at the Medical Research Council Cold Unit, had been passaged in volunteers but not in tissue culture. Approximately 25 tissue-culture infective loses $\left(\mathrm{TCID}_{50}\right.$ ) were administered as nasal drops. Back titrations performed after administration showed that one group of volunteers had received $21 \mathrm{TCID}_{50}$ and the other $10 \mathrm{TCID}_{50}$.

Volunteers-The studies were approved by the ethical committee at Northwick Park Hospital. ${ }^{11}$ Volunteers at the hospital and at the Common Cold Unit were selected and screened as described. ${ }^{912}$ Volunteers at the Common Cold Unit were screened for haematological and plasma biochemical abnormalities both before the trial and six days after virus inoculation-that is, three days after completing interferon treatment. They were isolated in groups of two or three. Clinical symptoms and signs of colds were assessed independently by JW according to the routine at the Common Cold Unit, ${ }^{12}$ and daily nasal secretion weights were measured as additional independent evidence of colds.

STUDIES

Kinetics of intranasal interferon-Five healthy volunteers at Northwick Park Hospital were each given seven separate doses of interferon 0 $\left(4 \times 10^{6} \mathrm{U} / \mathrm{ml}\right)$, using the Risdon spray gun ${ }^{1}$ calibrated to deliver 0.25 $\mathrm{ml}$ through a spray nozzle. One dose consisted of one spray per nostril (total dose $2 \times 10^{6} \mathrm{U}$ ) given to the volunteer sitting with the neck 7 extended. Nasal washings were collected at intervals from five to 60 minutes after dosing and the interval between doses was four to 16 hours. Antiviral activity in the nasal washings was assayed by determining the inhibition of cytopathic effect of Semliki Forest virus in embryonic bovine tracheal cells. Antigenic activity was determined by an immunoradiometric assay. The lower limits for detection of interferon were $10 \mathrm{U} / \mathrm{ml}$ by bioassay and $32 \mathrm{U} / \mathrm{ml}$ by immunoradiometric assay compared with the international standard preparation MRC 69/19B. Nasal washings from 22 volunteers who took part in the rhinovirus challenge study were also analysed. 